\title{
КРИМИНОЛОГИЧЕСКАЯ ХАРАКТЕРИСТИКА ЛИЦ, СОВЕРШИВШИХ ПРЕСТУПЛЕНИЕ В СФЕРЕ СЕМЕЙНО-БЫТОВЫХ ОТНОШЕНИЙ
}

\section{CRIMINOLOGICAL CHARACTERISTICS OF PERSONS COMMITTED A CRIME IN THE SPHERE OF FAMILY-DOMESTIC RELATIONS}

\section{Svetovtsov}

Summary: This article specifies the criminological characteristics of persons who have committed a crime in the field of family-domestic relations. In the study, the author relies on the following characteristics: gender, age, educational level, social status, psychophysiological indicators such as alcoholism or drug addiction, convictions, motive of the crime and the specifics of the conflict that provoked the crime. The study was carried out within the framework of two classifications. The first classification is based on the totality of relationships that make up the family-domestic sphere: family-domestic (relations between relatives), household (relations between neighbors), leisure-household (relations between friends and friends), production-household (relations between colleagues, colleagues). The second classification is based on the study of the personality types of the offender in accordance with the specifics of the criminal act: intentional attacks on life (Articles 105, 106, 107, $108,109,110.1$ of the Criminal Code of the Russian Federation), health (Articles 111, 112, 113, 114, 115, 116, 117, 118, 119, 125 of the Criminal Code of the Russian Federation), sexual inviolability and sexual freedom (Articles 131, 132, 133, 134, 135 of the Criminal Code of the Russian Federation), human property (Articles 158, 159, 161, 162, 163, 164, 165, 166,167 of the Criminal Code of the Russian Federation). The study was based on the study of materials from 441 criminal cases initiated in the Moscow region, a survey of those convicted of these crimes in the period 2018-2020. The author proves that for the objectivity of criminological research, a differentiated approach is needed to identify significant correlations.

Keywords: family-domestic relations, crimes in the field of familydomestic relations, identity of the offender, motives of family-domestic crimes, family-domestic conflict.

\author{
Световцов Михаил Михайлович \\ аспирант, Елецкий государственный университет \\ им. И.А. Бунина \\ svetovtsov@list.ru
}

Аннотация: В данной статье уточняется криминологическая характеристика лиц, совершивших преступление в сфере семейно-бытовых отношений. Автор в исследовании опирается на следующие характеристики: пол, возраст, уровень образования, социальный статус, психофизиологические показатели, такие как алкоголизация или наркотизация, судимость, мотив преступления и специфика конфликта, спровоцировавшего преступление. Исследование осуществлено в рамках двух классификаций. Первая классификация базируется на совокупности отношений, составляющих семейно-бытовую сферу: семейно-бытовые (отношения между родственниками), коммунально-бытовые (отношения между соседями), досугово-бытовые (отношения между друзьями и приятелями), производственно-бытовые (отношения между коллегами, сослуживцами). Вторая классификация основана на изучении типов личности преступника в соответствии со спецификой преступного деяния: умышленные посягательства на жизнь (ст. 105, 106, 107, 108, 109, 110.1 УК РФ), здоровье (ст. 111, 112, 113, 114, 115, 116, 117, 118, 119, 125 УК РФ), половую неприкосновенность и половую свободу (ст. 131, 132, 133, 134, 135 УК РФ), собственность человека (ст. 158, 159, 161, 162, 163, 164, 165, 166, 167 УК РФ). В основу исследования было положено изучение материалов 441 уголовного дела, возбужденных на территории Московской области, опрос осужденных по данным преступлениям в период 2018-2020 гг. Автор доказывает, что для объективности криминологического исследования необходим дифференцированный подход при выявлении значимых корреляций.

Ключевые слова: семейно-бытовые отношения, преступления в сфере семейно-бытовых отношений, личность преступника, мотивы семейно-бытовых преступлений, семейно-бытовой конфликт.
B последние годы в Российской Федерации все чаще подвергаются публичному обсуждению с оправданием или осуждением многие замалчиваемые темы, напрямую связанные с уголовным правом, деятельностью правоохранительных органов. Одной из наиболее злободневных тем подобного рода дискурсов является проблема семейно-бытового насилия. С одной стороны, это есть свидетельство растущего гражданского самосознания россиян, что предполагает в том числе и готовность отстаивать комплекс прав личности в правовом и общественном пространстве. С другой стороны, ажиотаж вокруг темы семейно-бытового насилия вызывается нарочитой публичностью современной культуры личной жизни.

Актуальность данной проблемы часто обусловливается громкими случаями, получившими публичную огласку, а также неудовлетворительной оценкой дея- 
тельности правоохранительных органов, системы уголовного права. Например, убийство А. Гусейновым своей девушки и ее несовершеннолетнего брата на Кубани, что сопровождалось онлайн-трансляциями преступлений. В эру непрофессионалов (деятельность профессионального сообщества корректируется с учетом непрофессиональных оценок) достаточно распространенным явлением выступает расхождения общественной и юридической правды. Например, И. Живова и ее дочь были подвергнуты насилию со стороны мужа, о чем жертва сообщила в социальных сетях до вынесения судебного решения, за что Никулинский суд Москвы постановил оштрафовать женщину.

Озабоченность также вызывают статистические данные, методы их сбора и анализа, поскольку на этих данных базируются направления деятельности правоохранительных органов. В официальной статистике Министерства внутренних дел Российской Федерации преступность в разрезе семейно-бытовой сферы отслеживается эпизодически. В научной литературе разброс оценок масштаба преступности в данной сфере отношений широк: $80 \%$ преступлений против жизни и здоровья человека (А.Н. Варыгин [2]); 53\% преступлений против жизни и 45\% против здоровья человека (О.Н. Ивасюк [5]), $25 \%$ преступлений против жизни и $17 \%$ против здоровья человека (М.Р. Нигматуллин [11]) и др.

К.Д. Титаев отмечает, что несовершенство статистического инструментария является серьезным препятствием при изучении преступности. В качестве примера исследователь приводит следующее противоречие: в официальной статистике по насильственным преступлениям отмечается, что в 73,9\% случаев жертва и преступник знакомы не были, только 11,2\% преступлений было совершено родственниками. Вместе с тем, большинство насильственных преступлений (88,6\%) совершаются в жилье жертвы или на прилегающей к нему территории. К.Д. Титаев справедливо замечает, что исходя из этих данных получается, что граждане свободно пускают к себе в жилье незнакомых людей. На самом деле, как считает автор, это противоречие порождается несовершенством методик сбора первичных данных [13].

Данные факты указывают на необходимость совершенствования уголовно-правовых норм, углубленного изучения криминологических аспектов многих социальных проблем. Исследование личности преступника в разрезе конкретного типа преступлений является основой системы превентивных мер. В научной литературе под личностью преступника понимается комплекс социальных, психологических и физических характеристик индивидуума, обладающих уголовно-правовой значимостью ввиду того, что они в целокупности повышают риск совершения субъектом преступных деяний определенного вида (Ю.М. Анто- нян [8], В.Н. Бурлаков [1], А.И. Долгова [7] и др.).

Как правило, при анализе личности преступника апеллируют к социально-демографической (пол, возраст образование и т.д.), социально-ролевой (социальный статус, связи и т.д.), нравственно-психологической (ценностная система) и уголовно-правовой (мотивация преступления, судимости) подсистемам личности. Данные показатели универсальны. В контексте исследуемой проблематики специфическими характеристиками личности семейно-бытового преступника с содержательной точки зрения является мотивация преступления, с процессуальной точки зрения - характер конфликта, обусловившего совершение преступления. Последний тезис отражает специфику семейно-бытовой преступности по сравнению с детерминантами большинства преступлений (К.А. Мясникова [9], П.А. Федоров, В.С. Харламов [14] и др.).

В самом обобщенном виде мотивы преступлений в сфере семейно-бытовых отношений трактуется как потребность преступника прекратить или изменить отношения с жертвой посредством причинения ему вреда. В научных источниках сложились два подхода к определению конкретных мотивов семейно-бытовых преступлений. Уголовно-правовой подход апеллирует к мотивам, детерминирующих конкретные виды преступлений: корыстные, корыстно-насильственные, насильственные [12]. Однако, следует отметить, что данный подход при изучении мотивов ограниченного круга преступлений излишне прямолинеен. Более перспективным нам представляется психологический подход, согласно которому мотивами семейно-бытовых преступлений рассматриваются враждебность, месть, ненависть, неприязнь, ревность, самоутверждения, сохранения отношений, корысть, оборонительные мотивы $[7,6]$.

Специфика конфликта, провоцирующего индивида на семейно-бытовое преступление, достаточно полно рассмотрена в работе К.А. Мясниковой. Автор в качестве видов семейно-бытовых конфликтов выделяет длительный конфликт, конфликтное поведение преступника, аморальный образ жизни преступника, острый конфликт, возникший в результате стрессового состояния преступника [9].

Таким образом, в качестве ключевых показателей, позволяющих всесторонне исследовать личность семейно-бытового преступника, в статье рассматриваются следующие: пол, возраст, уровень образования, социальный статус, психофизиологические показатели, такие как алкоголизация или наркотизация, судимость, мотив преступления и специфика конфликта, спровоцировавшего преступление.

Применительно к преступлениям в сфере семейно- 
бытовых отношений исследование специфики личности типичного преступника может быть осуществлено в рамках двух классификаций.

Первая классификация предполагает в качестве основного признака рассматривать совокупность отношений, составляющих семейно-бытовую сферу. Данные отношения классифицируются следующим образом: семейно-бытовые (отношения между родственниками), коммунально-бытовые (отношения между соседями), досугово-бытовые (отношения между друзьями и приятелями), производственно-бытовые (отношения между коллегами, сослуживцами). В рамках данной классификации выполнено исследование А.П. Некрасова, К.А. Насреддиновой [10].

Вторая классификация основана на изучении типов личности преступника в соответствии со спецификой преступного деяния. Такой подход присутствует в диссертационном исследовании В.С. Харламова. Автор рассматривает личность преступника сквозь призму насильственных внутрисемейных преступлений против жизни, здоровья членов семьи, ставящие в опасность жизнь или здоровье членов семьи, свободы, половые преступления, семьи и несовершеннолетних домочадцев, а также насильственные внутрисемейные преступления экономической направленности [15]. В настоящем исследовании вторая классификация представлена изучением личностей преступников, совершивших умышленные посягательства на жизнь (ст. 105, 106, 107, 108, 109, 110.1 УК РФ), здоровье (ст. 111, 112, 113, 114, 115, $116,117,118,119,125$ УК РФ), половую неприкосновенность и половую свободу (ст. 131, 132, 133, 134, 135 УК РФ), собственность человека (ст. 158, 159, 161, 162, 163, $164,165,166,167$ УК РФ).

В основу исследования было положено изучение материалов 441 уголовного дела, возбужденных на территории Московской области, опрос осужденных по данным преступлениям в период 2018-2020 гг.

В рамках первой классификации удалось установить, что в массиве преступлений в сфере семейно-бытовых отношений доминируют преступные деяния в досуговобытовой сфере (35,4\%), далее по нисходящей - собственно в семейно-бытовой (29,0\%), коммунально-бытовой $(24,5 \%)$ и производственно-бытовой $(11,1 \%)$ сферах.

Обобщенный портрет лица, совершившего преступление в досугово-бытовой сфере, следующий: это мужчина (в 79,5\% случаев) 18-29 лет (55,1\%), реже 30-49 лет $(21,8 \%)$, с преобладающим основным общим уровнем образования (34,6\%), однако возможны варианты: незаконченное общее образование $(28,2 \%)$ или среднее профессиональное образование $(25,6 \%)$, в большинстве случаев без постоянного источника дохода $(48,7 \%)$, воз- можные варианты: обучающийся (учащиеся школ, учреждений среднего профессионального образования, студенты) (25,6\%) или рабочий (16,7\%). Преступление совершено им в состоянии алкогольного $(73,1 \%)$ и/или наркотического $(25,0 \%)$ опьянения. Судимость выявлена у меньше половины респондентов (45,5\%). Наиболее распространенные преступления, которые совершают досугово-бытовые преступники, это преступления против здоровья $(64,7 \%)$, далее по нисходящей - против половой неприкосновенности и половой свободы (17,3\%), против жизни (10,3\%). Основные мотивы преступлений - это мотивы самоутверждения (30,1\%), неприязни $(17,9 \%)$ и враждебности (16,0\%). Провоцирующими факторами являются конфликтное, агрессивное поведение преступника (36,5\%), аморальный образ жизни (34,6\%), острый, внезапный конфликт (25,0\%).

Преступник в семейно-бытовой сфере - это мужчина $(61,7 \%)$, но доля женщин также велика в этой группе - 38,3\%. Вообще, как отмечают А.Н. Варыгин, Д.Ю. Яковлев [3], Н.А. Гришко [4], в семейно-бытовой сфере доля женщин-преступниц значительно выше, чем в общем разрезе преступности в целом и насильственной в частности. Далее, возраст семейно-бытового преступника - это чаще всего 30-49 лет (53,9\%), немного реже 18-29 лет $(39,1 \%)$. Образование доминирует основное общее (37,5\%), немного реже среднее профессиональное $(27,3 \%)$ или неполное основное общее $(24,2 \%)$ образование. Преступник наиболее часто либо рабочий (32,0\%), либо без постоянного источника дохода $(26,6 \%)$, либо служащие $(20,3 \%))$. Реже, но примерно в равной степени представлены в этой категории обучающиеся (10,9\%) и предприниматели (8,6\%). Большинство преступников в момент совершения преступления находились в состоянии алкогольного $(71,1 \%)$ и/или наркотического $(23,4 \%)$ опьянения. Судимость имели немногим больше половины преступников (51,6\%). Наиболее распространенные преступления - это преступления против здоровья (75,8\%), далее по нисходящей - против собственности $(11,7 \%)$, против жизни (10,9\%). Мотивы совершения преступлений в отношении родственников - это прежде всего ревность (39,1\%), желание самоутвердиться (30,5\%), а также сохранить отношения (22,7\%). Провоцирующими факторами преступлений в отношении родственников являются длительный конфликт $(41,4 \%)$ и враждебное поведение агрессора (21,9\%).

Коммунально-бытовой преступник - это, какправило, мужчина (82,4\%) в возрасте 30-49 лет (70,4\%), реже старше 50 (19,4\%) или в возрасте 18-29 лет (10,2\%). По показателю «образование» для этой категории преступников не выделяется доминирующий уровень: чаще всего это лица, имеющие основное общее образование $(38,0 \%)$, среднее профессиональное образование (31,5\%), высшее образование (15,7\%), неполное общее образование (14,8\%). Такая же ситуация наблюдается и по показателю 
«социальный статус» за исключением обучающихся, которые в данной категории не представлены (0,9\%): 29,6\% респондентов без постоянного источника дохода; 25,0\% - предприниматели; 19,4\% - рабочие; 13,9\% - пенсионеры; 11,1\% - служащие. Большинство коммунально-бытовых преступлений было совершено лицами, не находящимися в алкогольном или наркотическом опьянении (75,9\%). Большинство преступников (88,9\%) не имели судимости. Коммунально-бытовой преступник чаще всего покушается на здоровье граждан (76,9\%), собственность (12,0\%), жизнь (11,1\%). Преступлений против половой неприкосновенности и половой свободы среди коммунально-бытовых преступлений зафиксировано не было. Мотивами коммунально-бытового преступления чаще всего выступают враждебность (21,3\%), неприязнь $(18,5 \%)$, месть $(15,7 \%)$, ненависть $(12,0 \%)$. Коммунальнобытовое преступление в большинстве случаев было обусловлено длительным конфликтом (45,4\%), агрессивным поведением преступника (25,9\%).

Преступник в производственно-бытовой сфере - это значительно чаще мужчина $(89,8 \%)$ в возрасте 30-49 лет (75,5\%), реже 18-29 лет (22,4\%), у которого, как правило, среднее профессиональное образование $(73,5 \%)$, реже высшее образование (16,3\%). Лица из этой категории являются в большинстве случаев рабочими (87,8\%). Алкогольное или наркотическое опьянение, как и судимость не характерны для производственно-бытовой преступности. Производственно-бытовые преступления - это чаще всего преступления против здоровья человека (75,5\%), его собственности (14,3\%), редко жизни (10,2\%). Мотивы производственно-бытовых преступлений - это неприязнь $(36,7 \%)$ и корысть $(30,6 \%)$. Условия формирования преступного умысла - агрессивное поведение (51,0\%), длительный конфликт (38,8\%).

В рамках второй классификации в ходе эмпирического исследования было установлено, что с уголовноправовой точки зрения в структуре семейно-бытовой преступности доминируют преступления против здоровья человека (72,1\%), его жизни (10,7\%) и собственности $(10,7 \%)$, а также половой неприкосновенности и половой свободы (6,6\%).

Среди лиц, совершивших убийства, преобладают мужчины $(61,7 \%)$, однако доля женщин наиболее высока (38,3\%). Этот вывод согласуется с данными, полученными в результате диссертационного исследования В. С. Харламова: «Характерно, что из общего числа лиц (мужчин и женщин), совершивших криминальное насилие в семье, доля женщин-преступников имеет тенденцию к росту от менее тяжких к более тяжким» [7, с. 375]. Доминирующий возраст преступника - 30-49 лет (68,1\%), реже убийства совершают лица в возрасте 18-29 лет (25,5\%). По показателю «образование» среди семейно-бытовых убийц не наблюдается пиковых значений: $36,2 \%$ преступников имеют только уровень основного общего образования, 25,5\% - неполное общее образование, 23,4\% - среднее профессиональное образование, 14,9\% - высшее образование. Примерно такая же картина наблюдается и при применении показателя «социальный статус»: 36,2\% преступников рабочие, 27,7\% - не имеют постоянного источника дохода, 17\% являются предпринимателями, $14,9 \%$ служащими. Около половины убийств было совершено лицами, находящимися в состоянии алкогольного $(51,1 \%)$ и/или наркотического $(19,1 \%)$ опьянения. У большинства убийц (74,5\%) не было судимости. Большинство убийств происходит в досугово-бытовой (34\%), семейнобытовой (29,8\%), коммунально-бытовой (25,5\%), меньше - в производственно-бытовой (10,6\%) сферах. Наиболее распространенный мотивы убийств в семейно-бытовой сфере - это самоутверждение (31,9\%), ревность (25,5\%), попытка сохранить прежние отношения (23,4\%). Убийца формируется в результате состояния длительного конфликта (51,5\%), также провоцирует индивида на убийство жертвы, с которым его объединяют семейно-бытовые отношения, внезапная стрессовая ситуация, острый конфликт (36,2\%).

Лицо, совершившее преступление против здоровья другого человека, это, как правило, мужчина (79,9\%), хотя доля женщин в этой категории все еще велика $(20,1 \%)$. Возраст типичного преступника - 30-49 лет $(43,7 \%)$ или 18-29 лет (39,3\%). У этой категории преступников наиболее часто наблюдается среднее профессиональное образование (32,7\%) либо основное общее образование (31,8\%). Также велика доля преступников с неполным основным общим образованием (23,0\%). По социальному статусу преступники данной категории чаще всего рабочие $(29,9 \%)$ или без постоянного дохода $(28,6 \%)$. Также 13,5\% - это обучающиеся, 11,9\% - предприниматели, $10,7 \%$-служащие. Доля пенсионеров незначительна - 5,3\%. Больше половины данных преступлений осужденные совершили в состоянии алкогольного $(54,7 \%)$ и/ или наркотического $(17,0 \%)$ опьянения. Прежняя судимость зафиксирована у 39,6\% преступников. Чаще всего преступления против здоровья человека совершаются в среде досугово-бытовых (31,8\%), семейно-бытовых (30,5\%) и коммунально-бытовых (26,1\%) отношений, реже - в среде производственно-бытовых отношений (11,6\%). Мотивы преступников-агрессоров в семейнобытовой сфере - это неприязнь (18,6\%), самоутверждение $(17,0 \%)$, враждебность (16\%), месть (13,8\%) и ревность (13,8\%). Детерминантами совершения насильственных преступлений в семейно-бытовой сфере являются агрессивное, враждебное поведение преступника $(36,5 \%)$ и длительные конфликты с жертвой $(31,8 \%)$.

Насильники в выборке были только мужчины в возрасте 30-49 лет (62,1\%), реже в возрасте 18-29 лет (31,0\%). Среди преступников данной категории процент несовершеннолетних незначителен $(2,1 \%)$, также от- 
сутствуют лица старше 50 лет. По уровню образования преобладают преступники, имеющие среднее профессиональное образование $(41,4 \%)$ или только основное общее образование (37,9\%). Процент лиц с неполным основным общим образованием (13,8\%) или высшим образованием (6,9\%) относительно невысок. По показателю «социальный статус» выявлены 3 доминирующие категории граждан: без постоянного дохода (37,9\%), рабочие (27,6\%), обучающиеся (20,7\%). Среди насильников нехарактерны предприниматели (10,3\%), служащие (4,3\%). Почти половина половых преступлений была совершена в состоянии алкогольного опьянения (48,3\%), пятая часть - наркотического опьянения (17,2\%). Большинство насильников не имели судимости $(89,7 \%)$. Большинство преступлений против половой неприкосновенности и половой свободы произошли в сфере досугово-бытовых отношений $(93,1 \%)$, незначительная часть - непосредственно в сфере семейно-бытовых отношений (6,9\%). Мотивы изнасилований в семейно-бытовой сфере - это исключительно мотивы самоутверждения (96,6\%). Это преступление в большинстве случаев становится результатом аморального образа жизни насильника $(58,6 \%)$.

Преступники, совершившие преступные деяния против собственности, - это и мужчина $(51,1 \%)$, и женщина (48,9\%). Возраст такого преступника в большинстве случаев - 30-49 лет (57,4\%), реже - 18-29 лет (25,5\%). 14,9\% всех преступников данной категории - лица старше 50 лет. Образование у такого преступника - либо уровень основного общего образования $(40,4 \%)$, либо уровень среднего профессионального образования (38,3\%). Реже встречаются преступники с высшим образованием (17,0\%). Более половины всех преступников данной категории - лица с непостоянным источником дохода $(57,4 \%)$ либо рабочие $(23,4 \%)$. Реже это обучающиеся $(8,5 \%)$. Доля служащих $(4,3 \%)$, пенсионеров $(4,3 \%)$ и предпринимателей (2,1\%) незначительна. Большинство преступников в момент совершения преступления находилось в трезвом состоянии (46,8\%), 38,3\% были под воздействием алкоголя, 14,9\% - под воздействием наркотиков. Большинство преступников (70,2\%) на момент совершения преступления не имело судимости. Данный вид преступлений совершается во всех сферах семейно-бытовых отношений: 31,9\% - непосредственно в семейно-бытовой сфере, 27,7\% - в коммунально-бытовой сфере, 25,5\% - в досугово-бытовой сфере, 14,9\% - в производственно-бытовой сфере. Мотивы у преступников этой категории - это исключительно корысть (96,4\%). Как правило, преступления против собственности в семейно-бытовой среде становятся результатом аморального образа жизни преступника (48,9\%).

Как видно из проведенного анализа личности семейно-бытового преступника, для объективности криминологического исследования необходим дифференцированный подход для выявления значимых корреляций. В целом, обладают статистически достоверным значением следующие признаки. Во-первых, несмотря на то, что в массиве семейно-бытовой преступности доминируют мужчины (76,2\%), доля женщин по сравнению с аналогичной корреляцией в разрезе общей преступности достаточно высока (23,8\%). Наиболее частым возрастом семейно-бытового преступника является 30-49 лет (49,0\%). Изучение уровня образования и специфики занятости осужденных позволяет сделать вывод о невысоком социальном статусе преступника. Отмечается большая вероятность его алкоголизации или наркотизации по крайней мере в момент совершения преступления (69,2\%). Как правило, доминируют мотивы самоутверждения, неприязни, ревности, враждебности. Провоцирующим фактором совершения семейно-бытового преступления является длительный конфликт с жертвой, а также агрессивное, враждебное поведение преступника.

ЛИТЕРАТУРА

1. Бурлаков В.Н. Назначение наказания и личность преступника: теоретические, правовые и методические вопросы / В.Н. Бурлаков. - Санкт-Петербург: Юридический центр, 2017. - 198 с.

2. Варыгин А.Н. Особенности семейно-бытовых преступлений и их предупреждения / А.Н. Варыгин // Вестник Казанского юридического института МВД России. - 2014. - № 3(17). - С. 30-34.

3. Варыгин А.Н., Яковлев Д.Ю. Преступления против жизни, совершаемые женщинами: криминологическая характеристика, особенности мотивации и предупреждения: монография / А.Н. Варыгин, Д.Ю. Яковлев. - Москва: Юрлитинформ, 2017. - 154 с.

4. Гришко Н.А. Преступное насилие, совершаемое женщинами в семейно-бытовой сфере: монография / Н.А. Гришко. - Москва: Юрлитинформ, 2020. - 139 с.

5. Ивасюк 0.Н. Криминологические особенности семейно-бытовых преступлений / 0.Н. Ивасюк // Вестник Московского университета МВД России. - 2015. - № 7. - С. 153-156.

6. Ильяшенко А.Н. Мотивы насильственных преступлений, совершаемых в сфере семейных отношений / А.Н. Ильяшенко // Российский следователь. 2002. - № 12. - C. 20-23.

7. Личность преступника и ее криминологическое изучение / под редакцией профессора А.И. Долговой. - Москва: Российская криминологическая ассоц., 2018. $-195 \mathrm{c}$.

8. Личность преступника и профилактика преступлений: монография / Антонян Ю.М. и др.; под ред. Ю.М. Антоняна. - Москва: Проспект, 2017. - 220 с.

9. Мясникова К.А. Мотивы преступного насилия в быту / К.А. Мясникова // Философия права. - 2012. - № 2 (51). - С. 128-132. 
10. Некрасов А.П., Насреддинова К.А. Социально-демографическая характеристика личности преступника, совершившего бытовые преступления, и их причины / А.П. Некрасов, К.А. Насреддинова // Вестник Челябинского государственного университета. Серия: Право. - 2015. - Вып. 41, № 4 (359). C. 158-162.

11. Нигматуллин М.Р. Виктимологическая характеристика жертв семейно-бытовых преступлений / М.Р. Нигматуллин // Виктимология. - 2017. - № 4(14). C. 29-32.

12. Старков 0.В. Предупреждение преступлений: учебное пособие / О.В. Старков. - М.: Юристъ, 2005: Щербин. тип. - 283 с.

13. Титаев К.Д. Насильственная преступность в России: жертвы и преступления: аналитический обзор / К. Д. Титаев. — СПб: Институт проблем правоприменения при Европейском университете в Санкт-Петербурге, 2019. — (Аналитические обзоры по проблемам правоприменения; вып. 2(2019)). — 16 с.

14. Федоров П.А., Харламов В.С. Криминологический анализ преступлений в семейно-бытовой сфере на современном этапе / П.А. Федоров, В.С. Харламов // Вестник Санкт-Петербургского университета МВД России. - 2011. - № 3 (51). - С. 118-123.

15. Харламов В.С. Теория и практика противодействия преступному насилию в семье: системное криминологическое и уголовно-правовое исследование: диссертация ... доктора юридических наук: 12.00.08 / Харламов Валентин Станиславович. - Санкт-Петербург, 2018. - 719 с.

(с) Световцов Михаил Михайлович (svetovtsov@list.ru).

Журнал «Современная наука: актуальные проблемы теории и практики»

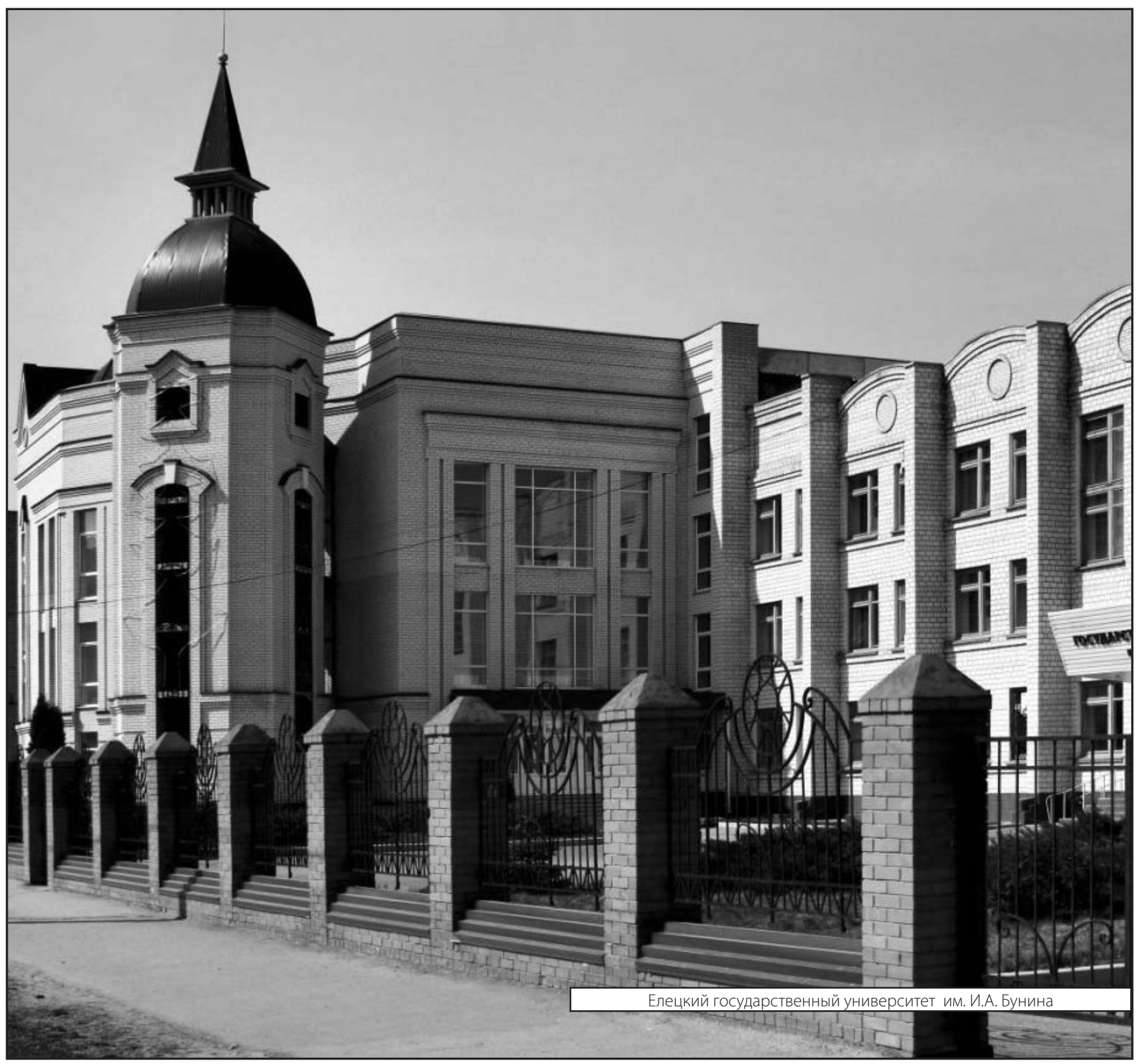

